\title{
La riqueza del Archivo Torriglia. Su aporte a la historia de las instalaciones portuarias rosarinas
}

The richness of the Torriglia Archive. Its contribution to the history of Rosario's port facilities

Ricardo V. Acursso, Adriana De Biasi, Sofía Fernández y Lucrecia Silvani

\section{(2) OpenEdition}

\section{Journals}

\section{Edición electrónica}

URL: http://journals.openedition.org/corpusarchivos/247

DOI: $10.4000 /$ corpusarchivos. 247

ISSN: 1853-8037

Editor

Diego Escolar

Referencia electrónica

Ricardo V. Acursso, Adriana De Biasi, Sofía Fernández y Lucrecia Silvani, «La riqueza del Archivo

Torriglia. Su aporte a la historia de las instalaciones portuarias rosarinas », Corpus [En línea], Vol 3, No 1 | 2013, Publicado el 15 junio 2013, consultado el 22 abril 2019. URL : http://journals.openedition.org/ corpusarchivos/247; DOI : 10.4000/corpusarchivos.247

Este documento fue generado automáticamente el 22 abril 2019.

Licencia Creative Commons: Atribución-NoComercial 2.5 Argentina (CC BY-NC 2.5 AR) 


\section{La riqueza del Archivo Torriglia. Su aporte a la historia de las instalaciones portuarias rosarinas}

The richness of the Torriglia Archive. Its contribution to the history of Rosario's port facilities

Ricardo V. Acursso, Adriana De Biasi, Sofía Fernández y Lucrecia Silvani

\section{NOTA DEL EDITOR}

Fecha de recepción del original: 18/04/2013

Fecha de aceptación para publicación: 18/05/2013

\section{Introducción}

1 El fondo documental que compone el Archivo Torriglia, resguardado en el Centro de

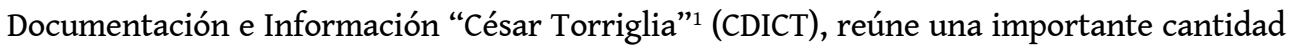
de documentos de valiosa información procedente de la actividad profesional de especialistas de la agrimensura.

2 Esta colección particularmente focalizada en la propiedad territorial fue donada por el agrimensor César Torriglia a la Facultad de Humanidades y Artes en el año 1973, por aquel entonces Facultad de Filosofía y Letras, otorgándole a esa cesión el carácter de adhesión al vigésimo quinto aniversario de su fundación.

Dos aspectos importantes deben señalarse en la valoración de este acto de donación por el agrimensor Torriglia. En primer lugar, se trataba de una colección particular formada por archivos que fue adquiriendo en forma personal: "En el curso de 47 años de actividad profesional y por el sesgo que ella le imprimió, le hizo necesario reunir antecedentes adquiriendo archivos y acrecentándolos. El así formado alcanzó proyecciones históricas 
por su volumen y extensión"'. En segundo término, el objetivo preciso del acto de donación, tal como lo expresara en nota dirigida al Sr. Decano de esa casa de estudios, “...mi deseo es que el material que resulta del esfuerzo de recopilación de generaciones anteriores y de toda mi vida, esté abierto a la más amplia consulta del público"3.

Si bien no se dispone en este Centro de mayor información relativa a los criterios de adquisición e integración del Archivo por parte de su donante, algunas breves notas biográficas podrían contribuir con la interpretación de este proceso.

Nacido en la localidad de Correa (Santa Fe), el $1^{\circ}$ de febrero de 1905, Torriglia fallece en Rosario el 27 de febrero de 2000. Cursó sus estudios en la Universidad Nacional del Litoral, de la que egresó con el título de Agrimensor en el año 1925. Posteriormente, desempeñó cargos técnicos en las municipalidades de Rosario y Cañada de Gómez. Amigo personal del Dr. Lisandro de la Torre, fue diputado provincial electo por el departamento Iriondo (Partido Demócrata Progresista), en el período 1932/1935. En dicha oportunidad presidió la Comisión Interparlamentaria de Desagües. A lo largo de su actividad profesional se especializó en problemas de la agrimensura relacionados con el derecho y en materia de tasaciones de inmuebles. Desarrolló trabajos vinculados a pericias judiciales, mensuras en juicio de deslinde, reivindicatorios e informaciones posesorias, perito tasador y juicios de expropiación.

\section{Composición y naturaleza del repertorio documental Torriglia}

1. Período histórico: entre mediados de los siglos XIX y XX con una profundidad que remite al siglo XVI.

2. Área geográfica: provincias de Santa Fe (fundamentalmente), importante proporción en la de Córdoba y, en menor medida, las de Buenos Aires, Mendoza, San Luis, San Juan, Santiago del Estero y Región Chaco-Paraguaya.

3. Composición: alrededor de 1.400 documentos, 6.000 planos y 20 libros de asiento (anotaciones referidas a tierra, legislación, contratos, etc.).

4. Tipo de documento: diligencia de mensura (relación de antecedentes, informes y planos); división de condominio; mensura judicial; denuncia de tierra; extracto de títulos; juicio de expropiación; peritaje judicial; proyecto de subdivisión de campo; tasación; copia de testamentaria; árbol genealógico; trazado de pueblos y colonias; urbanización; instalación de servicios públicos; proyecto de trazado de caminos y calles; red e instalación ferroviaria; etc.

Ejemplos de documentos:

Skinner, Juan y Reid, Enrique. Antecedentes y división de condominio. Campo "Los Algarrobitos". Pedanía Bell Ville. Departamento Unión. Provincia de Córdoba. 1906.

Vallet, Alejo. Denuncia de isla fiscal. Departamento San Javier. Provincia de Santa Fe. 1901.

Middleton, Enrique. Extracto de escrituras compra de campo en Colonia Carmen. Pedanía La Carlota. Departamento Juárez Celman. Provincia de Córdoba. 1905.

Landeta, Nicolás. Juicio de evicción y saneamiento de terreno. Rosario. Departamento Rosario. Provincia de Santa Fe. 1902.

Molina, Juan Bernabé. Mensura de campo. "Los Desmochados". Departamento Iriondo. Provincia de Santa Fe. 1872.

Reales y Morales, José. Testamentaria. 1869. 
Replanteo de la Avenida Belgrano, desde el muelle del Ferrocarril Oeste Santafesino hacía el muro de Gas. Rosario. Departamento Rosario. Provincia de Santa Fe. 1903.

Colonia Gessler. Extracto del informe de la mensura judicial de la colonia. Provincia de Santa Fe.1886.

Colonia Lheman. Trazado de las colonias. Departamento Castellanos. Provincia de Santa Fe. 1882.

Ferrocarril Central Argentino. Mensura administrativa de tierras entregadas por el Gobierno de Santa Fe. Departamento San Martín. Provincia de Santa Fe. 1866.

Carlos Casado (sucesión). Mensura de las propiedades en el Chaco Paraguayo. 1908.

Alvear, Diego. Estado del expediente de mensura. 1869.

Banco Hipotecario Nacional. Mensura del campo la Zarunga. Departamento 28 de Marzo. Provincia de Santiago del Estero. 1893.

Jefes y Oficiales de la Guerra con el Paraguay. Lista de las adjudicaciones y decreto de adjudicaciones de terrenos de campo. 1865.

Casado, Carlos y linderos. Antecedentes, títulos y mensuras de campo en departamento La Paz. Provincia de Mendoza. 1856.

Punta del Agua. Estancia. Informe sobre el proyecto de irrigación. Departamento Jachal. Provincia de San Juan. 1912.

Informe del juicio seguido por la Empresa Ferrocarril Pacífico contra la Comisión de Fomento de Aarón Castellanos. Laguna La Picasa. Año 1925. Peritaje judicial.

Urraco, Pedro. Antecedentes de títulos de campo, compra a la Junta de Temporalidades, banda sur del Carcarañá. Tierras de la estancia San Miguel. Provincia de Santa Fe. 1775.

7 Las siguientes publicaciones dan cuenta de las investigaciones que se nutren de este repositorio como fuente documental:

Locatelli, D. (1974). Historia de la propiedad territorial en el Municipio de Rosario. Rosario: Dirección General de Topografía y Catastro. Municipalidad de Rosario.

Roldán, D. P. (2005). Del Ocio a la Fábrica. Sociedad, espacio y cultura en Barrio Saladillo. Rosario 1870-1940. Rosario: Prohistoria ediciones.

Videla, O. R. (2006). La burguesía rosarina ante las transformaciones y límites del modelo agroexportador (corporación y regulación del mercado entre fines del siglo XIX y los comienzos del siglo XX). La Bolsa de Comercio de Rosario. Tesis Doctoral. Facultad de Humanidades y Artes. Universidad Nacional de Rosario.

Dalla Corte, G. (2009). Lealtades firmes. Redes de sociabilidad y empresas: la "Carlos Casado S.A." Entre la Argentina y el Chaco Paraguayo (1860-1940). Madrid: Consejo Superior de Investigaciones Científicas.

Lanciotti, N. S. (2009). De rentistas a empresarios. Inversión inmobiliaria y urbanización en la Pampa argentina. Rosario, 1880/1914. Santa Fe: Universidad Nacional del Litoral.

Pradella, M. C.; Deblasi, S. M.; Brambilla, L.; Ibarra D.; Alonso, S.; Álvarez Colombres, M. J. (2012). Pueblo Álvarez. Orígenes y fundación. Rosario.

\section{Aporte del corpus documental a la historia de las instalaciones portuarias rosarinas.}

8 En consideración a la riqueza de información que atesora este archivo, nos hemos planteado como objetivo para el presente trabajo ilustrar sobre el valioso aporte del material documental a la historia de las instalaciones portuarias rosarinas procediendo a la selección de informes periciales por juicios de expropiación y reivindicación en 
terrenos del Bajo de la ciudad, epicentro de la actividad portuaria, sector en donde particulares y la empresa del Ferrocarril Central Argentino reclamaban reconocimiento de sus derechos de posesión a la Sociedad Constructora del Puerto de Rosario con motivo de las obras de construcción del mismo iniciadas en 1902.

Los informes periciales seleccionados son simplemente una muestra de los numerosos e interminables pleitos suscitados en esos terrenos de ribera. Los documentos 19 y 31 constituyen peritajes judiciales en los autos de los juicios de expropiación "Sociedad Constructora Puerto del Rosario con Manuel Cilveti", peritos actuantes los agrimensores Pedro A. Vinent y Leslie G. Barnett en el primero y Vinent y Ramón de Escauriza, en el segundo. El documento 1015 "Ferrocarril Buenos Aires y Rosario (hoy Central Argentino) con sucesión de Manuel Cilveti. Reivindicación”, perito designado el Ingeniero Casiano Rojas. Si bien los asuntos que se ventilan datan del primer decenio del siglo XX, los mismos proporcionan al estudioso valiosa información cuya profundidad histórica se remite a fines del siglo XVII.

Los puntos centrales fijados para la pericia fueron los siguientes:

[...] si es cierto que los terrenos pretendidos por la parte demandada se encuentran ubicados en su totalidad dentro de la playa o ribera interna del río Paraná limitada por la cota más 5,20 metros que fijó el Gobierno Nacional como línea donde llegaban las más altas aguas de aquel río en sus crecientes ordinarias" y "en caso de existir terrenos correspondientes a la ribera interna ${ }^{5}$, establecer las dimensiones exactas de los mismos [...]. (Documento 19, foja 1).

11 El laborioso estudio de los elementos de juicio indispensables para expedirse sobre dichos puntos, demandó de los profesionales un pormenorizado examen de los antecedentes de los títulos, remontándose al origen de la propiedad en los terrenos del Bajo.

En la exposición de este asunto ofreceremos, en primer lugar, una descripción del período histórico de la información documental en general y de los antecedentes del puerto de Rosario. Seguidamente daremos cuenta del contenido de los documentos en los aspectos sobre los que hemos focalizado nuestra atención, extractando algunos párrafos que consideramos de interés.

\subsection{Breve descripción del período histórico de la información documental}

Los terrenos de aluvión limitados por la barranca se conocían como de la ribera o el bajo. Hacia el año 1873, por Ordenanza aprobada en fecha 13 de junio, se establece la delineación de la ciudad según la cual esta quedaba dividida en cuatro sectores urbanos, a saber:

El Bajo: franja ocupada por las actividades portuarias.

Zona adyacente al río Paraná desde el pie de la barranca hasta la lengua de agua.

Entre la punta de la barranca Norte (actuales calles Sarmiento y Jujuy) hasta la

barranca de los Sauces (hoy encuentro de las calles Chacabuco y Mendoza).

Ciudad: área de máxima posibilidad de consolidación a corto y mediano plazo.

Dentro de estos límites y en las adyacencias de la zona de ribera se ubica al casco

histórico.

Extramuros: sector contemplado como de consolidación previsible a largo plazo.

Suburbios: terrenos con preeminencia rural pero formando parte de la ciudad. 
Mapa 1. E - 0351. CDICT. Sección plano Municipal. Ciudad de Rosario. Nicolás Grondona. Año 1871. Referencias: 1) Casco histórico; 2) Puerto - sector del Bajo; 3) Punta Barranca de los Sauces; 4) Punta Barranca Norte; 5) Bajada Grande; 6) Estación Ferrocarril Central Argentino.

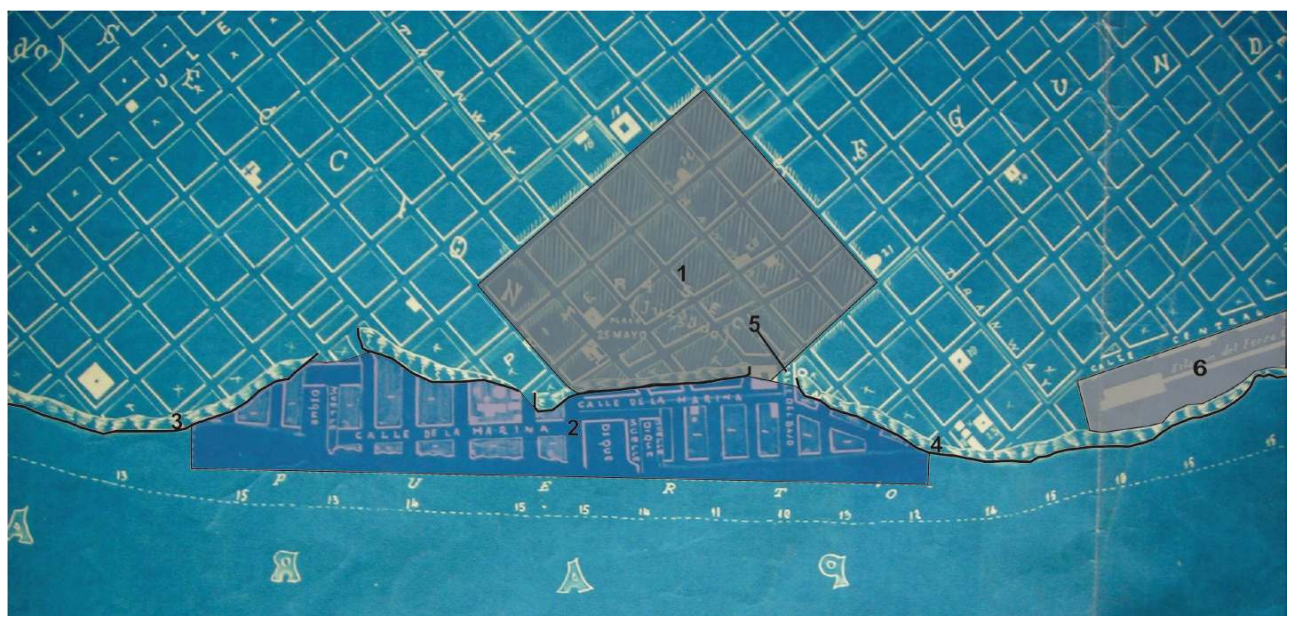

El sector del Bajo favorecido por las condiciones naturales de su ribera se constituiría rápidamente en una importante vía fluvial de entrada a Rosario, el movimiento comercial y de pasajeros pronto convertirían a la actividad portuaria en el motor de la acelerada transformación de la urbe en los aspectos económico, urbanístico y social.

esarrollo de las colonias y de la producción agrícola ganadera en general del centro y sur de la provincia de Santa Fe demandaría la puesta en marcha de un sistema de transporte conformado por las vías navegables, el ferrocarril y las instalaciones portuarias.

El lugar geográfico privilegiado de Rosario y la gran profundidad del río Paraná frente a sus costas la convirtió desde época temprana en un puerto natural. Su desarrollo se acelera a partir de la caída del gobierno de Juan Manuel de Rosas (1852), el enfrentamiento entre la Confederación urquicista y el Estado de Buenos Aires (1853-1861) y la Guerra del Paraguay (1865-1870). Hacia fines del siglo XIX y principios del XX, la guerra anglo-boer también favorecía al puerto rosarino convertido en una de las bases desde donde el Imperio británico obtenía sus suministros para atacar a los colonos holandeses de Sudáfrica.

La ciudad de Rosario alcanzaría notoriedad y prestigio transformándose en el principal puerto de la Confederación. Este factor condujo a un acelerado proceso de urbanización simultáneo con el crecimiento demográfico. En 1858 la urbe contaba con 9.780 habitantes, pasando a tener 23.169 en 1869, alcanzando 50.914 en el año 1887, así como 112.461 en 1900 y para el Centenario de la República, 192.278.

Por ambos lados de la antigua Bajada Grande, eje del movimiento portuario (hoy Bajada Sargento Cabral), fueron estableciéndose numerosos muelles de madera más o menos precarios, que las crecidas deterioraban o directamente destruían. La gran facilidad que las altas barrancas y la playa con frente al canal del río brindaban a las operaciones de carga, hizo que durante décadas no se avanzara en la edificación de un puerto moderno.

En el Bajo, extendido hacia la actual calle España en su límite norte y por el sur hasta el Boulevard 27 de Febrero, se alzaron, con el correr del tiempo, unos veinticinco muelles mayormente de empresas privadas, depósitos y graneros, siendo los más famosos los de Carlos Casado del Alisal. Este empresario castellano, a través del Ferrocarril Oeste 
Santafesino, librado al servicio público en 1883, transportaba la producción agrícola de la Colonia Candelaria (hoy ciudad de Casilda) -también creada por él-y del resto del sur santafesino hacia el puerto rosarino, donde había construido grandes silos por entonces únicos en América del Sur. Con la exportación de la producción de trigo de dicha colonia en 1878, Casado se convierte en el primer exportador de cereales del Cono Sur Latinoamericano a Europa.

Baste decir que los graneros del Rosario pueden contener treinta y cinco mil fanegas de trigo y recibir, pesar, clasificar, limpiar, y poner en la bodega de un buque, sesenta toneladas por hora! Este edificio que es una gloria industrial de la Provincia de Santa-Fé [sic], cuyas riquezas agrícolas revela, se hace aun más importante si se reflexiona que es el único de su género que existe en la América del Sud, y que naciones tan poderosas y ricas como Italia, España, Holanda y Alemania, no los tienen aún.

En efecto, solo Inglaterra, Francia y Estados Unidos, comparten con la modesta Provincia de Santa-Fé [sic], el honor de tener edificios especiales, para graneros a vapor.

Estos graneros pertenecen a una sociedad anónima formada por acciones. Ellos vienen a llenar una necesidad que era muy sentida en el Rosario, donde concurren para ser embarcados todos los granos que se cosechan, no sólo en las colonias de la Provincia de Santa-Fé [sic], sino también todos los que se producen en las provincias del interior, y que vienen a ser vendidos en el mercado de Buenos Aires, o son remitidos a Europa, directamente del Rosario.

(El Diario, Buenos Aires 22 de diciembre de 1881, en Carrasco, 1886, p. 507).

período histórico de la información detallada en estos informes periciales corresponde precisamente al momento de plena expansión y florecimiento del puerto rosarino que concentraba el movimiento comercial y de pasajeros en simultáneo con el extraordinario crecimiento de la producción cerealera de la pampa gringa. "En estos años, la ciudad incrementó su comercio con los puertos europeos a través de varias líneas de navegación (inglesas, alemanas, españolas y belgas) que la conectaban con el continente europeo" (Venesia, 2001, p. 341)

21 En palabras de Gabriel Carrasco, el puerto de Rosario no solamente era el más cómodo de la república, sino también el más económico.

El flete de Europa hasta el Rosario cuesta lo mismo o menos que hasta Buenos Aires, no obstante que hay ochenta y dos leguas más de viaje.

$\mathrm{Y}$ esto se explica fácilmente por el mayor riesgo que corren los que van a aquel puerto y por los grandes gastos que son necesarios para operar el desembarque de las mercaderías, pues fondeando los buques de ultramar a dos y más leguas de los muelles, tienen que hacer la descarga por medio de lanchas con gran demora y costo, mientras que en el Rosario descargan directamente sobre la tierra firme, sin más trabajo que colocar una planchada entre el buque y el muelle.

Los seguros son también más baratos en el Rosario que en Buenos Aires, por iguales causas. (Carrasco, 1886, p. 177).

Hacia fines del siglo XIX la conjunción de las necesidades y de los reclamos de los sectores dirigentes locales y del apoyo de los Estados nacional y provincial hizo posible la concreción del proyecto para dotar a la ciudad del puerto que exigía su desarrollo económico-social.

\subsection{Antecedentes del puerto de Rosario}

El desenvolvimiento de las actividades de carga y descarga fluvial en la costa rosarina datan de la época hispánica, como lo atestiguan una serie de documentos. Destaca entre 
ellos uno que ha estudiado y publicado el historiador Boleslao Lewin (1957) que se remonta a la década de 1740. Este autor hace referencia al contrabando o comercio intérlope practicado por vecinos del entonces villorrio. Práctica común en la región rioplantense, y necesaria para la supervivencia de la zona, dada la insuficiencia del comercio legal -controlado por la Corona española - para satisfacer las necesidades de la población.

Suelen considerarse como las primeras instalaciones rosarinas las concesiones a perpetuidad otorgadas por el Estado nacional en el sector del Bajo, en terrenos que a estos fines comprara al Gobierno provincial. Los contratos de concesión se otorgaron a los empresarios Esteban Rams y Rubert y Eduardo Hopkins. Este último conocido como el muelle de Hopkins, se constituiría en la Sociedad de Muelles de Rosario cuya concesión pasaría posteriormente a manos de Aarón Castellanos en primer término, luego a Aldao y Díaz, quienes con posterioridad lo venden al Gobierno nacional. Por otra parte, hacia el año de 1859, el empresario Ignacio Comas compra al Gobierno provincial una fracción de terreno adyacente al muelle de Hopkins en donde construiría muelles y otras instalaciones portuarias.

Ya en fecha más tardía, en 1888, Juan Canals organiza la Sociedad Anónima del Puerto de Rosario de Santa Fe, que se declara en quiebra cuando la crisis económica mundial de 1889-1890, no pudiéndose materializar el proyecto.

Superada esta etapa de crisis económica, la concesión fue finalmente adjudicada a la Sociedad Constructora del Puerto de Rosario (la firma Hertsent et Fils asociada a Schneider y Compañía), por el término de 40 años. La ejecución de las obras de modernización de la infraestructura portuaria se inició en el año 1902 y el nuevo puerto se libró al servicio en 1906. Los muelles estaban instalados a lo largo de la Avenida Belgrano.

Colección de postales. Museo de la Ciudad. Año 1902.

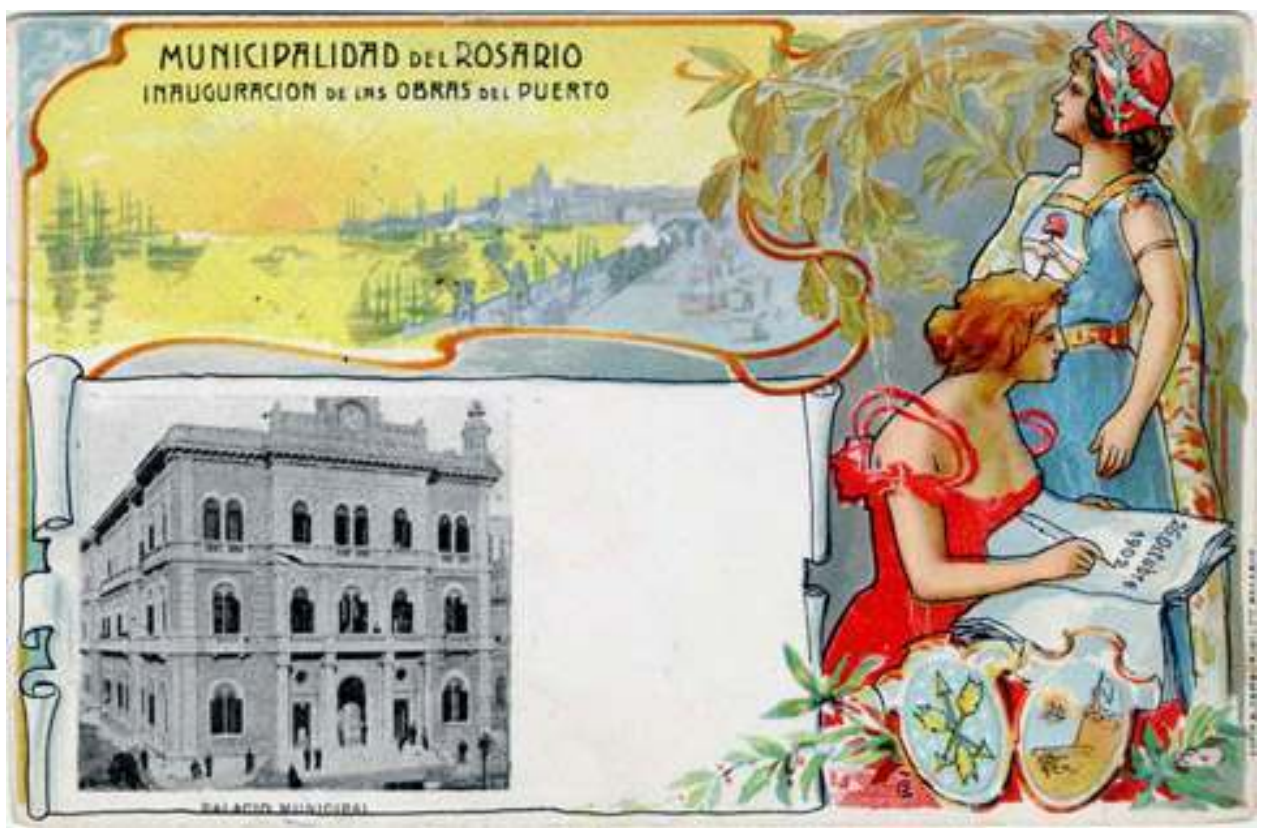

En este proceso de transformación que abrió la etapa de florecimiento de la actividad portuaria, ciudad y puerto se identificaban. Consecuentemente, la urbe experimentó 
marcadas variaciones en la fisonomía ribereña del sector del Bajo. En un principio, el escaso desarrollo del comercio fluvial durante el período colonial no hacía necesaria la construcción de instalaciones que interviniesen significativamente en la alteración del paisaje de esta zona de playa, pero el acelerado crecimiento del movimiento portuario a partir de la década de 1850 introdujo paulatinamente sustanciales modificaciones urbanísticas a raíz de la construcción de la infraestructura necesaria para el desenvolvimiento del puerto a la altura de las exigencias del comercio fluvial en expansión. Tal ha sido el producto de estos cambios que resulta imposible reconocer la existencia de la otrora ribera natural, la que fuera zona de playa y barranca testigo del nacimiento de un gran puerto alrededor de la antigua Bajada Grande.

\subsection{Extractos de los informes periciales}

28 La valoración de los datos que aporta cada documento puede variar en razón de las diferentes lecturas a la que es sometido su contenido. En el material de referencia nos interesa resaltar algunos de sus atributos, resultado del pormenorizado examen de los antecedentes de los títulos de propiedad motivo de los pleitos, así como de la verificación de mensuras y relacionamientos denunciados por otros agrimensores. Estas investigaciones concretadas por los peritos en cumplimiento de su cometido proporcionan una valiosa y precisa información acerca de las siguientes cuestiones:

1) Origen y evolución de la propiedad en el sector del Bajo rosarino y conflictos vinculados a derechos de posesión y ubicación de terrenos como resultado de la imprecisión en la redacción de los títulos de propiedad e imperfecciones de las mensuras en la época colonial.

2) Maniobras especulativas seguidas por algunos propietarios de los lotes de terreno en dicho sector de la ciudad a raíz de su potencialidad económica, la que se tornaba más evidente al promediar el siglo XIX.

3) Razón de las imperfecciones de las mensuras en la época colonial.

\subsubsection{Origen, evolución y conflictos sobre la propiedad de los terrenos en el sector del Bajo rosarino}

La disparidad de criterios aplicados para determinar el límite oriental de los lotes cuya superficie se extendía hasta la zona de barranca adyacente a la playa, desencadenó numerosas cuestiones de conflicto por derechos de posesión. Estas imprecisiones tienen su origen en la redacción del título de propiedad de la Merced Real otorgada al Capitán Luis Romero de Pineda, origen de la ciudad de Rosario. En la división de la merced en lonjas por sucesión y posteriores enajenaciones, se utilizaron indistintamente estos criterios, otorgando a las escrituras un carácter ambiguo causante de los pleitos a los cuales se ha hecho referencia.

Entre los diversos títulos de las diversas fracciones en que se subdividieron las lonjas que en conjunto formaron los terrenos de la ciudad del Rosario que se llamó la merced real á Don Luis Romero de Pineda, encontramos que en uno se le dá por frente al naciente de la barranca del río Paraná; en otros el pié de la misma barranca; y vários se establece por cabecera la lengua del agua del río Paraná.

Estas distintas denominaciones del límite oriental de las lonjas ha originado numerosas cuestiones desde mucho tiempo atrás, y es precisamente su interpretación la que ahora ocasiona la diferencia de criterio para la apreciación de 
las superficies a expropiar por la Sociedad Constructora del Puerto y por los particulares que tienen título o posesión de terrenos con frente al río Paraná.

Como cesionario de acciones y derechos, los particulares pretenden hacer llegar su dominio hasta la línea del agua del río, y la Sociedad Constructora que ha ocupado yá los terrenos indispensables para las obras, sostiene ser de dominio del Estado, de consiguiente un bien público, una buena porción de las tierras que ha ocupado y que los particulares pretenden les sea expropiada.

En una de las distintas cuestiones que con diverso fin se ventilaron yá anteriormente ante el Gobierno de la Provincia de Santa Fé, cuestión promovida por Don Antonio Berdier en su carácter de denunciante de los terrenos del bajo frente al Saladillo, el Ministro General, entonces Doctor Don Juan Francisco Segui resuelve el punto reconociendo por límite oriental de los terrenos de la merced o de arriba de la barranca, al pié de ésta, y declara fiscales los comprendidos entre dicho pié y el agua del río. (Documento 31, foja 39). originado, por una parte, entre los varios terrenos declarados donados o vendidos como fiscales, y por otra, la resolución de Seguí que sólo reconoce al pie de barranca como límite oriental de los terrenos con frente al río en el sector del Bajo, declarando como fiscal la superficie que se extiende entre esta y la lengua de agua según la curva de nivel. Estas diferencias de criterio al momento de fijar el límite oriental suscitaron innumerables pleitos a través del tiempo; ejemplo de ello es el caso que nos ocupa, verificándose la cuestión de litigio hacia comienzos del siglo XX.

En el marco de la enredada madeja que representa la evolución de la propiedad de los terrenos del Bajo, es necesario explicar el origen de la pretensión de los herederos de Manuel Cilvetti (parte demandada en el juicio de expropiación), sobre lo que consideraban les correspondía del sector de aluvión. En tal sentido, debemos retrotraernos a la compra del Sr. Cilvetti de un lote de terreno sobre la barranca y que por aquello de la imprecisión en la fijación del límite oriental de los terrenos con frente a la misma, le venden los derechos y acciones del área de playa adyacente al referido lote, siendo esta fracción entre el pie de la barranca y la lengua de agua la que da lugar al pleito con la Sociedad Constructora del Puerto de Rosario.

El origen del título del Sr. Cilveti es la venta efectuada en 1858 por don Mariano Rivera a doña Manuela S. de Rusignol, (...) en el terreno alto hasta dar con la barranca con la cual lindaba con el naciente (Escribano Ignacio Llobet)

En 1859 la Sra. Rusignol lo vende á Ramon Baró, en 1860 Baró á la misma Sra. Rusignol; en 1863, dicha señora á Julio Zuviría y Roges, Adolfo; y en 1866, Zuviría y Roges al General Nicolás Vega.

Hasta aquí el título lindaba al naciente con la barranca; pero, como entre la barranca y el río existe una gran extensión de terreno bajo, vendida por el Gobierno á Don Ignacio Comas, los herederos del General Vega para vender lo que no les pertenecía le pusieron este agregado al enajenar el inmueble en 1883 a Ernesto Covalier6: 'siendo entendido que si hubiera más terreno, quedará a favor del comprador como también quedan a su favor todos los derechos que la parte vendedora tuviese a los terrenos de aluvión hasta la lengua del agua.

Por medio de este simple añadido, estiraron en 1883 el título que lindaba al Naciente con la barranca, para hacerlo ocupar todo el bajo hasta el río; y Don Manuel Cilveti al comprar en 1886 se creyó autorizado a posesionarse de lo que nunca correspondió a sus causantes. (Documento 19, fojas 6 y7. Resaltado en el original).

En foja 22 del mismo documento, al hacer referencia a la escritura de venta de los herederos de Vega a Ernesto Covalier y en particular a los derechos de aluvión o hasta la 
lengua de agua, los vendedores pretendieron legitimar esta cesión de derechos fundándose en los títulos antiguos.

Siendo entendido que si hubiera más terreno quedará a favor del comprador, como también quedan a su favor todos los derechos que la parte vendedora tuviera a los derechos de aluvión o hasta la lengua del agua, según los títulos antiguos. (Documento 19; foja 22. El resaltado nos pertenece).

\subsubsection{Maniobras especulativas sobre algunos terrenos del Bajo} Rojas en el documento 1015.

Ante todo debo manifestar á V.S. que teniendo desde antigua data estudios prolijos practicados sobre estos terrenos y conciencia clara de su ubicación y origen tendré que diferir de las conclusiones de mis honorables colegas, no con el ánimo de defender á una de las partes en litigio, sea o no el perito de esa parte, sino porque los estudios practicados laboriosa y concienzudamente me llevan a esos resultados aún contra las opiniones é informes de otros honorables colegas que en mi concepto están equivocados y esa común equivocación ha llevado a los propietarios de los terrenos de rivera (sic.) en ese paraje a pleitos sin número é interminables como los que se han suscitado, tales como los caratulados Octavio J. Molina con Antonio Santa María; Casado con Comas; Comas con la Empresa del Gas; etcétera, etcétera. Pienso también, que el perito técnico, en sus funciones de tal, debe de investigar las verdades basado en su ciencia y experiencia y que sus conclusiones fundadas sean el resultado claro de su trabajo sin mirar si ellas favorecen ó vulneran a la parte que le ha propuesto o a la contraria.

Con este criterio paso a estudiar los antecedentes de este juicio. (Documento 1015, foja 1).

Resulta interesante señalar las diferencias respecto a las manifestaciones de dominio de los terrenos de Ignacio Comas observadas en el documento 1015 en comparación con los documentos 19 y 31. Mientras que en los dos últimos los peritos Ramón de Escauriza, Pedro A. Vinent y Leslie G. Barnett mencionan a Ignacio Comas como único comprador de las 500 varas al Estado provincial, las que seguidamente fracciona y vende a Juan Pablo López y Ricardo Foster, el ingeniero Casiano Rojas demuestra que este bien inmueble escriturado a favor del Sr. Comas, era en realidad propiedad de los condóminos Comas, López y Foster dejando en evidencia una situación irregular en donde sucesivas ventas de unos a otros y a terceros son solo simulaciones con un interés meramente especulativo, que tenía por objeto unas veces hacer elevar los precios para sacar mayor partido en la expropiación de los terrenos y otras para facilitar acciones deducidas contra la Municipalidad.

[...] Por los documentos extractados se ve claramente que las quinientas varas compradas por Comas al Gobierno de la Provincia (...) fueron divididas en ocho lotes (...) correspondiendo del uno al nueve á López, Foster, Comas, López, Foster, Comas, López, Foster, Comas.

En realidad de verdad no se trataba de ventas de Comas a López y Foster, sino de división de condominio del terreno escriturado a nombre de Comas, pero que pertenecía por iguales partes a Comas, López y Foster. La división en lonjas de 
55varas y $1 / 2$ respondía a hacer una división de equitativo valor dado el mayor precio que tenían los lotes del Norte más cercanos á lo poblado y a los muelles establecidos, es decir al verdadero puerto.

Ya veremos más tarde como se multiplican estas simulaciones de ventas tan propias del carácter del célebre Ignacio de quién se decía que tenía más dobleces y entrepaños que el órgano de la Catedral de Milán. (Documento1015, foja 6).

Plano 2. P - 0887. CDICT. Referencias: 1) Fracción de 500 varas escriturada a nombre de I. Comas; 2) Manzana donde se ubica el terreno alto propiedad de M. Cilvetti y el terreno bajo pretendido, en sus adyacencias; 3) Barranca; 4) Río Paraná.

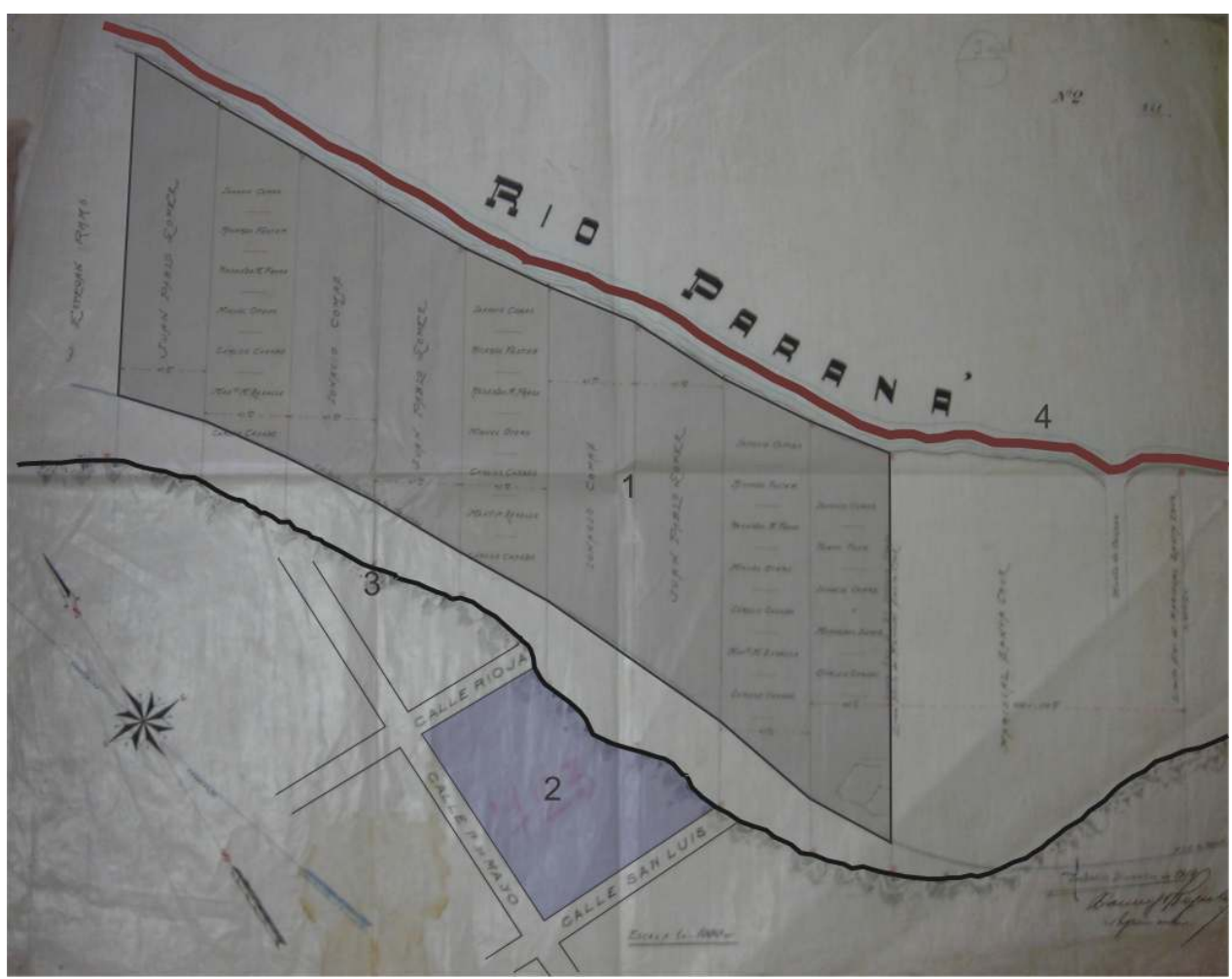

Este informe pericial describe detalladamente todas las ventas y transferencias de que fueron objeto las 500 varas compradas al Estado provincial. Sobre el particular concluye diciendo el agrimensor C. Rojas, "[...] Como se observará por los documentos extractados los célebres terrenos de Comas han sido doblemente vendidos por sus propietarios, salvo que existiera un documento anulatorio de los títulos Nos. 10 y 11" (Documento 1015, foja16).

Es así como el pormenorizado examen de títulos que demandó el análisis de los antecedentes del terreno pretendido por los herederos de M. Cilvetti nos introduce, a través del documento 1015, en maniobras de tipo especulativo por personas destacadas de la elite local sobre esa propiedad de 500 varas, simultáneas a su explotación para el comercio fluvial. El mencionado Sr. Comas instaló en el lugar y como ya expresáramos, muelles, almacenes y una fábrica de almidón, edificando su casa en las adyacencias.

Casa del Sr. Comas.- Una de las más pintorescas por su posición y forma. Situada entre las calles Santa-Fé [sic], 25 de Diciembre y Bajo, con entrada por las tres, y teniendo el primer piso al nivel del puerto, y el tercero á la altura de la calle SantaFé A su frente se encuentran las obras de los muelles en construcción, propiedad también del Sr. Comas, y por ellos pasa el ramal del Ferro-Carril Oeste que une el puerto con la parte alta de la ciudad. 
Con posterioridad a la impresión de esta lámina, el mismo propietario ha edificado a continuación (á la izquierda del grabado) otra casa de dos pisos que tiene media cuadra de extensión, con lo cual ha mejorado mucho esa parte del barrio. (Carrasco 1886, p.603)

\subsubsection{Mensuras en la época colonial} recurren a la descripción de la medición hecha al galope. La transmisión de ese conocimiento técnico como aclaratoria necesaria para quienes debían dictaminar sobre el asunto del pleito, aporta al contenido del documento un valor didáctico más allá del propósito específico del informe pericial.

[...] en los tiempos primitivos la medición de la tierra pública se hacía por pilotos, en medio de mil dificultades, en terrenos sin recursos, en pais [sic.] no dominado aún y por consiguiente expuestos al ataque de los indios, -lo que obligaba á proceder con la mayor celeridad posible si bien sacrificando la exactitud de la operación.-

El procedimiento generalmente seguido era como sigue:

El piloto colocaba la brújula ó aguja de marear en el punto determinado como de arranque y mandaba colocar una bandera en la dirección del horizonte que correspondía al Norte ó al medio rumbo magnético que estaba convenido,-y estirando la cuerda que se confrontaba ante los interesados con una vara de medir, procedía á la mensura de la distancia que estipulaba la merced.- Estas cuerdas que se usaban, á veces de cuero crudo medían cien varas castellanas, se prendían generalmente á la cincha de dos caballos cuyos ginetes [sic.] llevaban una caña, y mientras que uno de ellos permaneciendo á caballo fijaba en tierra la caña que aproximaba al extremo de la cuerda, el otro ginete galopaba las cien varas hasta estirar la cuerda, en cuyo extremo fijaba su cañana y permanecía firme (tanto como lo permitía el caballo) hasta que el compañero hiciera la misma operación y pasara delante. (Véase Chapeaurrouge, Tratado de Agrimensura, Tomo II).

De aquí provienen, no solamente las notables diferencias de arrumbamiento que se encuentran para una misma línea, verificadas con los instrumentos y procedimientos modernos, sinó [sic] también las diferencias existentes entre la medición escrita y la antigua medición en el terreno, hechas al "galope". (Documento 19, fojas 3 y 4 . Resaltado en el original)

\section{Conclusiones}

En el transcurso del presente artículo nos hemos propuesto demostrar el aporte de este archivo de agrimensores a la historia regional y local. Para estos fines hemos procedido a la descripción general del repertorio y particularmente de un tipo de documento, informe pericial, seleccionando asuntos referidos a expropiaciones en el sector del puerto de la ciudad de Rosario. 
En correspondencia a lo expresado en el párrafo anterior y a modo de síntesis o cierre, deseamos destacar tres aspectos fundamentales con referencia a las características más relevantes de esta colección documental:

Su importancia reside en la calidad y diversidad de la información contenida en la documentación que la compone.

Conforma un repositorio privilegiado que adquiere el carácter de fuente documental de consulta indispensable, permitiendo seguir el proceso del régimen territorial, las características del movimiento poblacional, la fundación de pueblos y colonias, la conformación del espacio urbano y rural, el surgimiento de redes sociales y elites locales, el establecimiento de entidades y organizaciones civiles, el trazado de redes ferroviarias y camineras, inversión inmobiliaria y urbanización, entre los grandes temas vinculados a la naturaleza de su contenido.

Brinda a los usuarios la posibilidad de acceso a la información de dominio y parcelaria en un solo lugar, acreditada en expedientes testamentarios, extractos de títulos, relaciones y antecedentes de mensuras, preservando en muchos casos

\section{Vistas parciales del puerto rosarino en diferentes momentos de su historia}

Rosario. Año 1866 - Gentileza Escuela de Museología

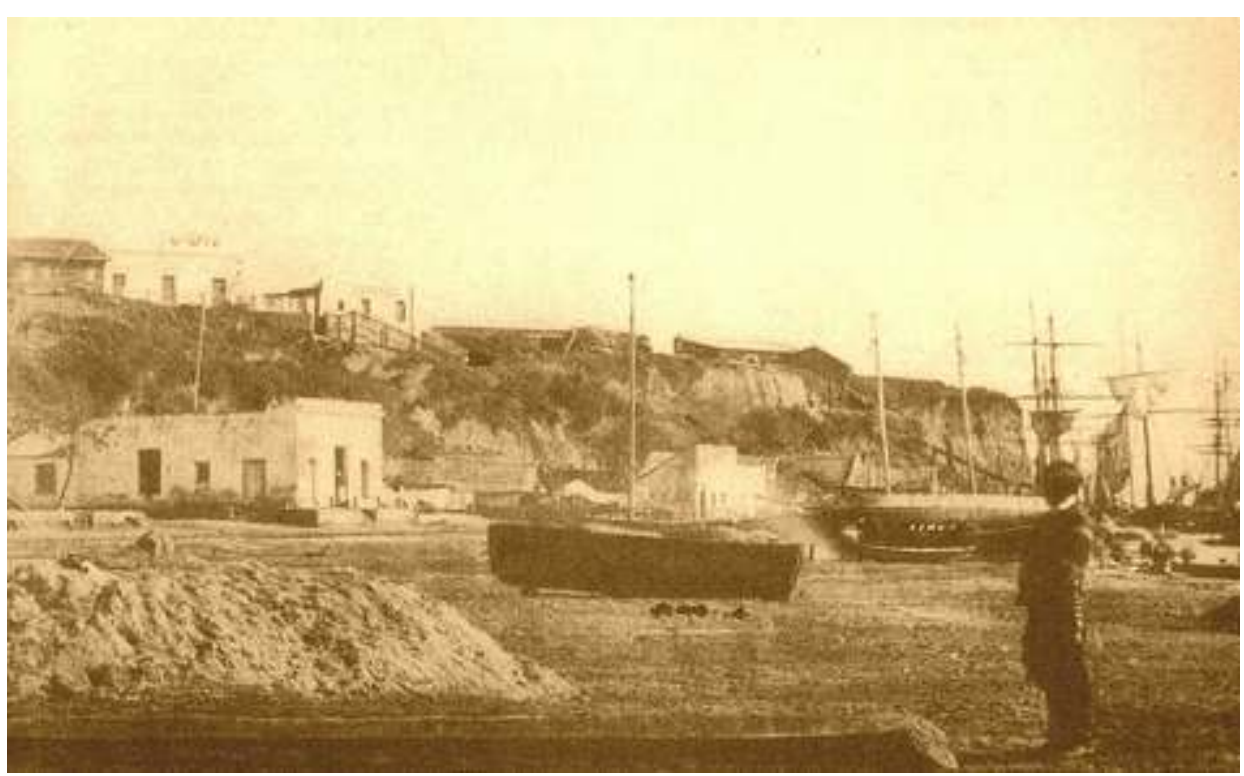


Fleuty, Eduardo. Rosario de Santa Fe. Litografía, 1875. Museo de la Ciudad. Se diferencian claramente la Bajada Grande, la playa y la barranca.

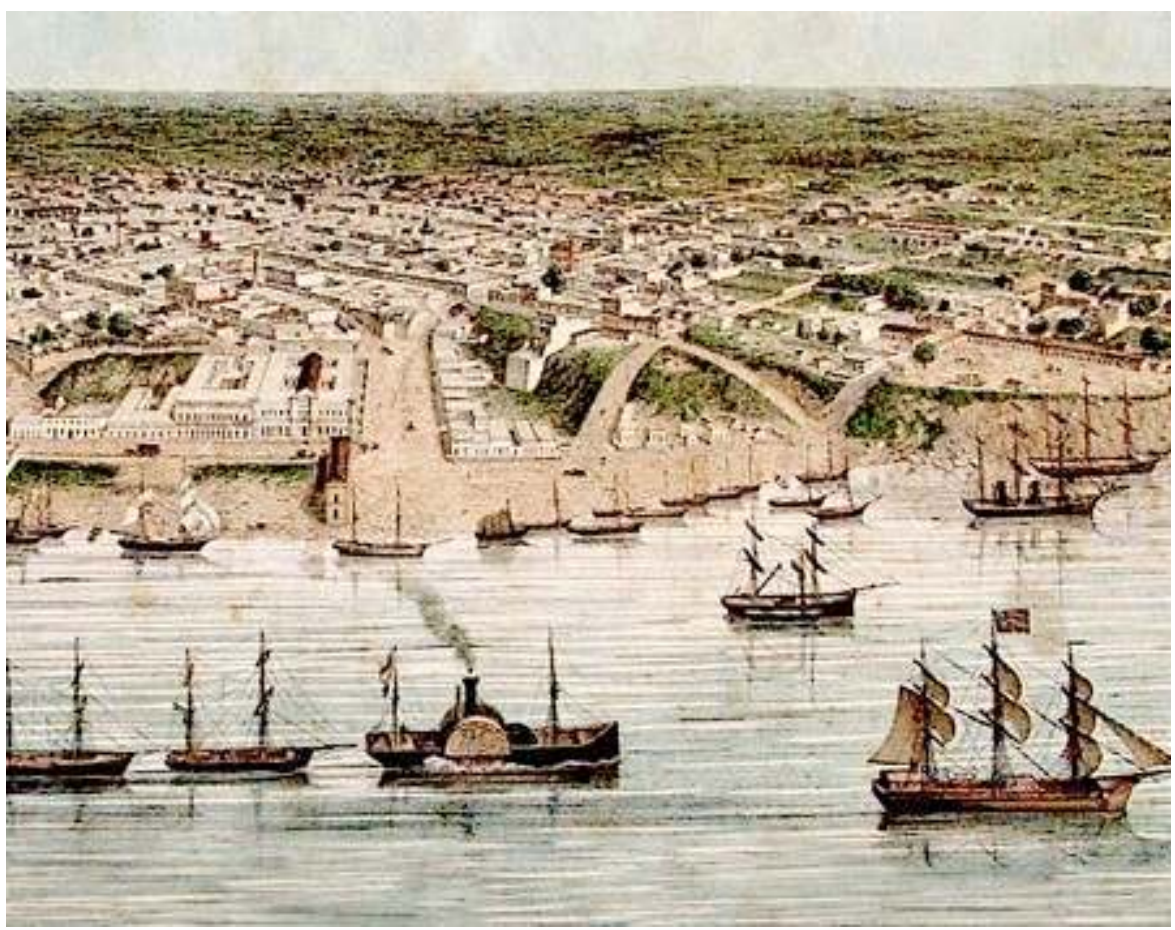

Vista del puerto de Rosario. Año 1868. Museo de la Ciudad.

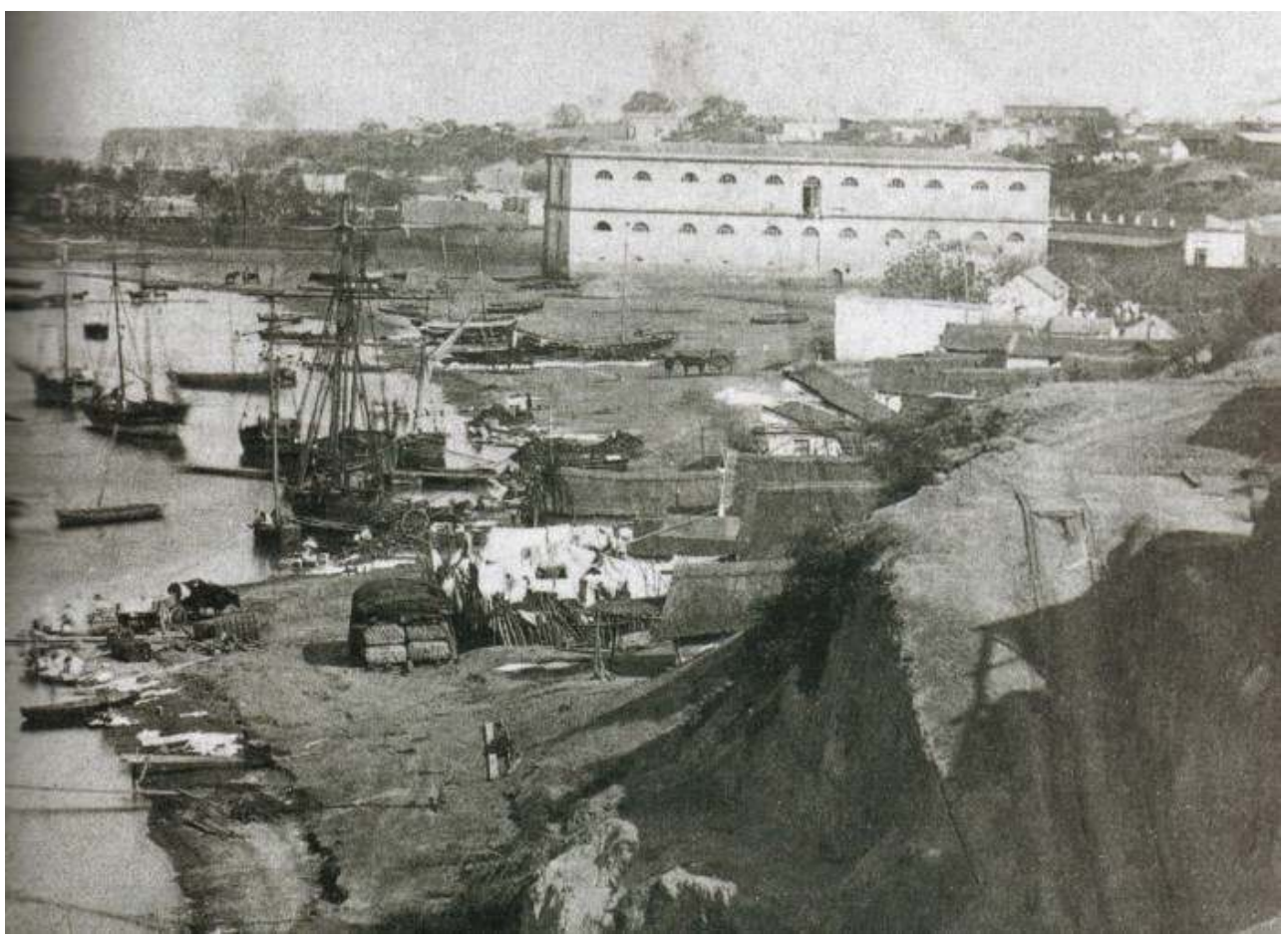


Postal - d. 1870

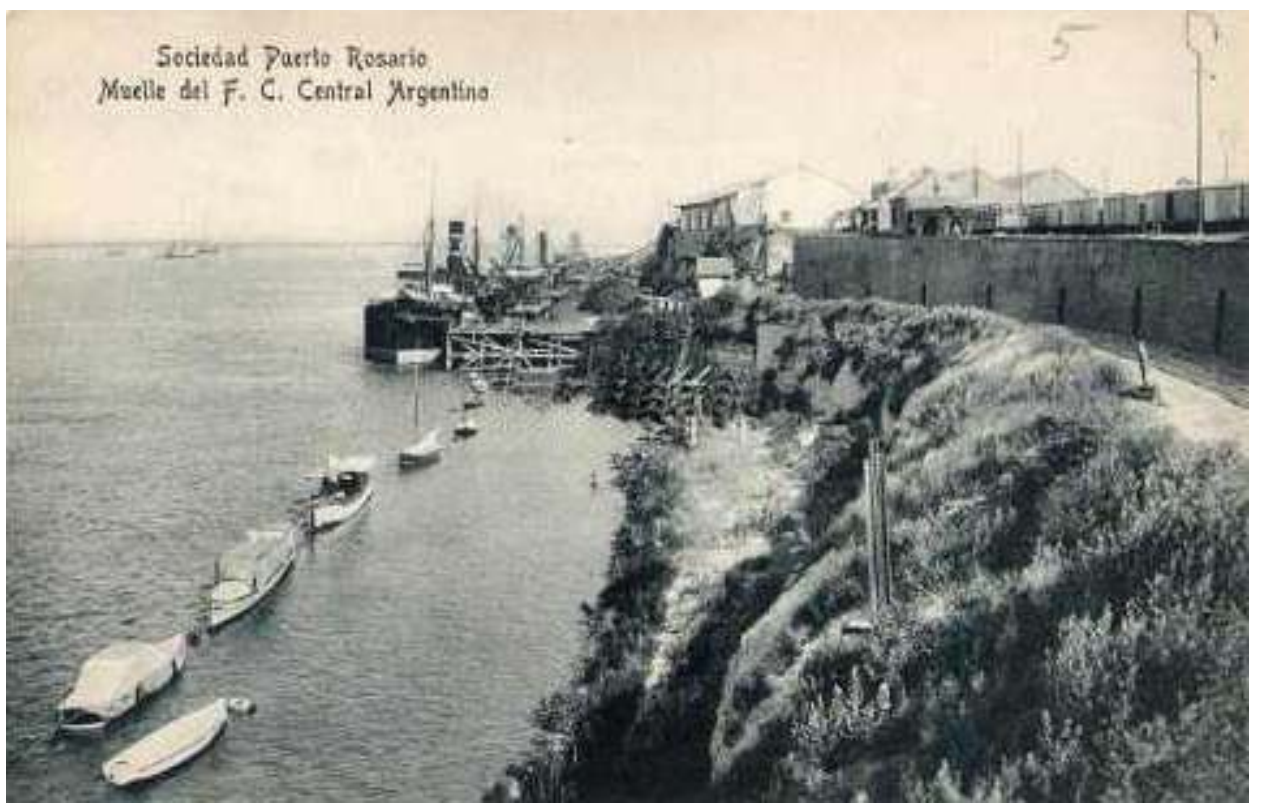

Túnel del Ferrocarril Central Argentino. Rosario - c. 1884.

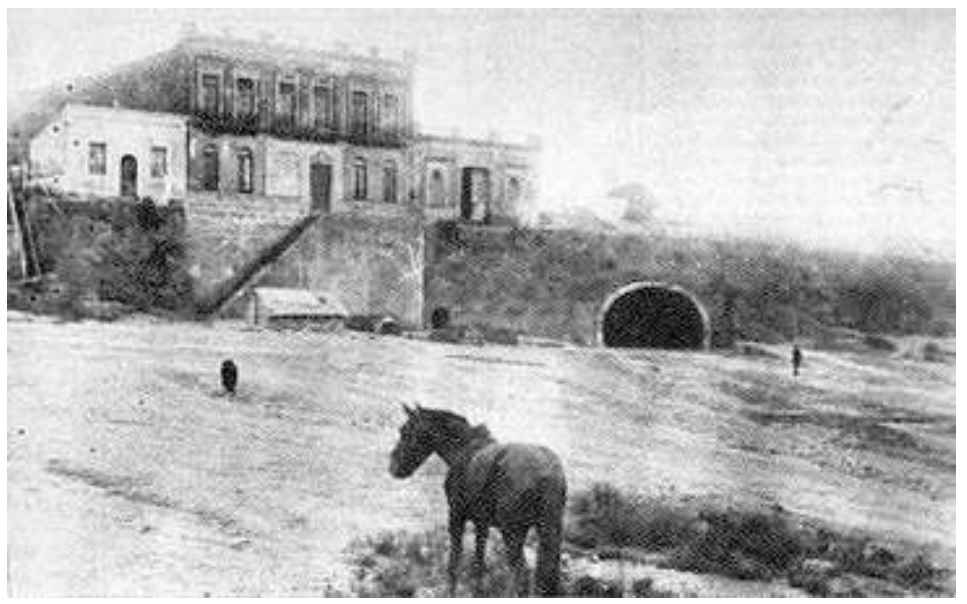


Muelles de A. Castellanos.

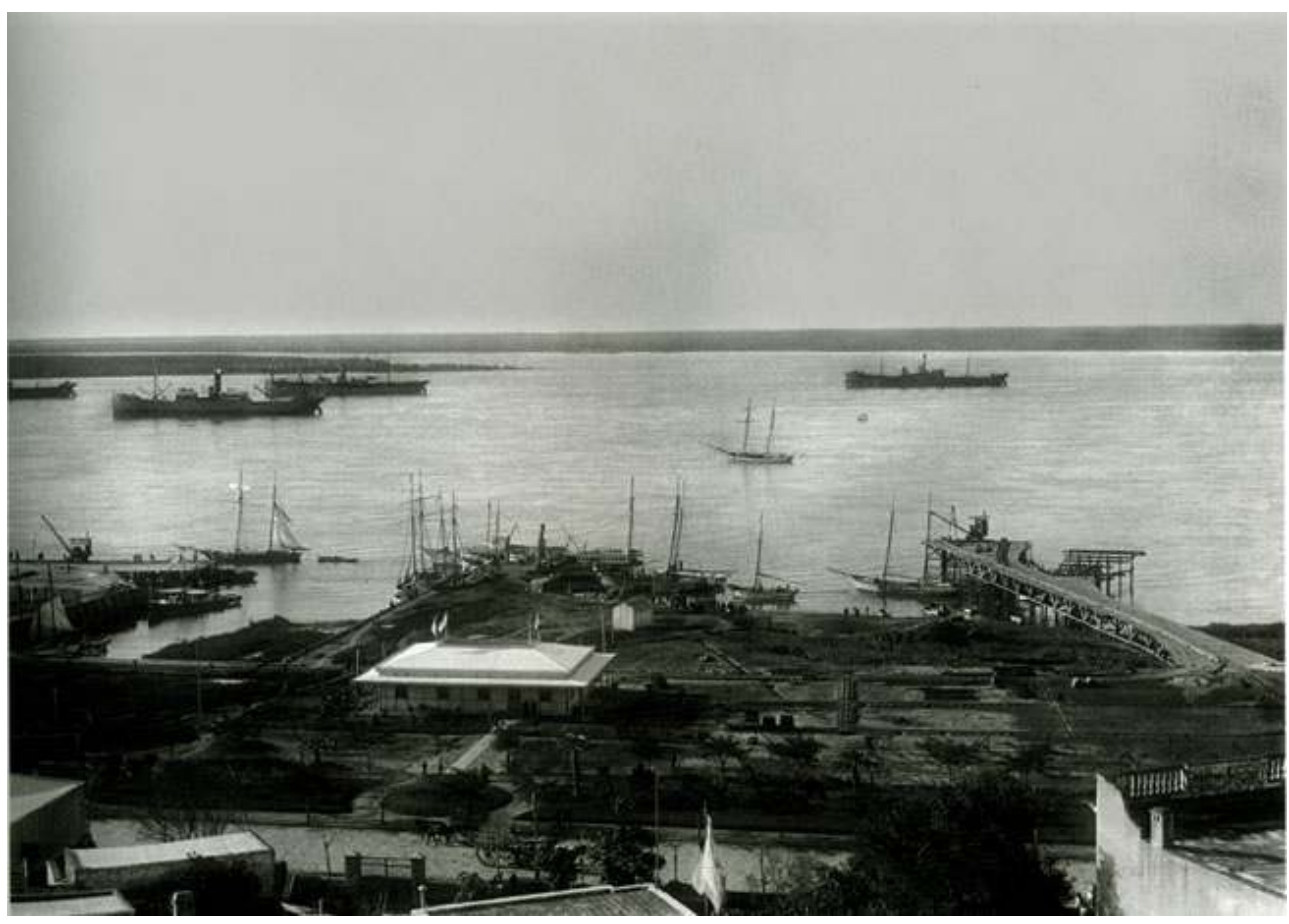

Muelle. Puerto de Rosario. Año 1900

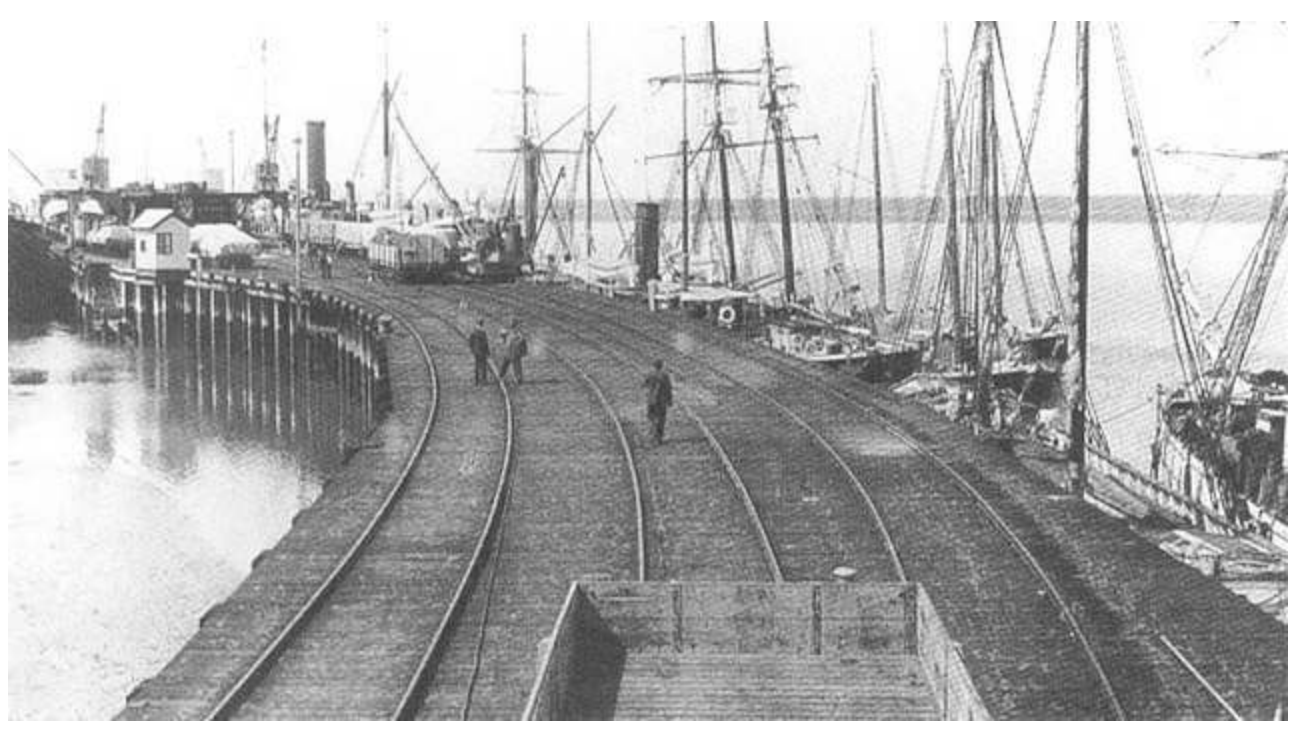


Casa de I. Comas. Plancha 11. Carrasco 1886, p. 242.

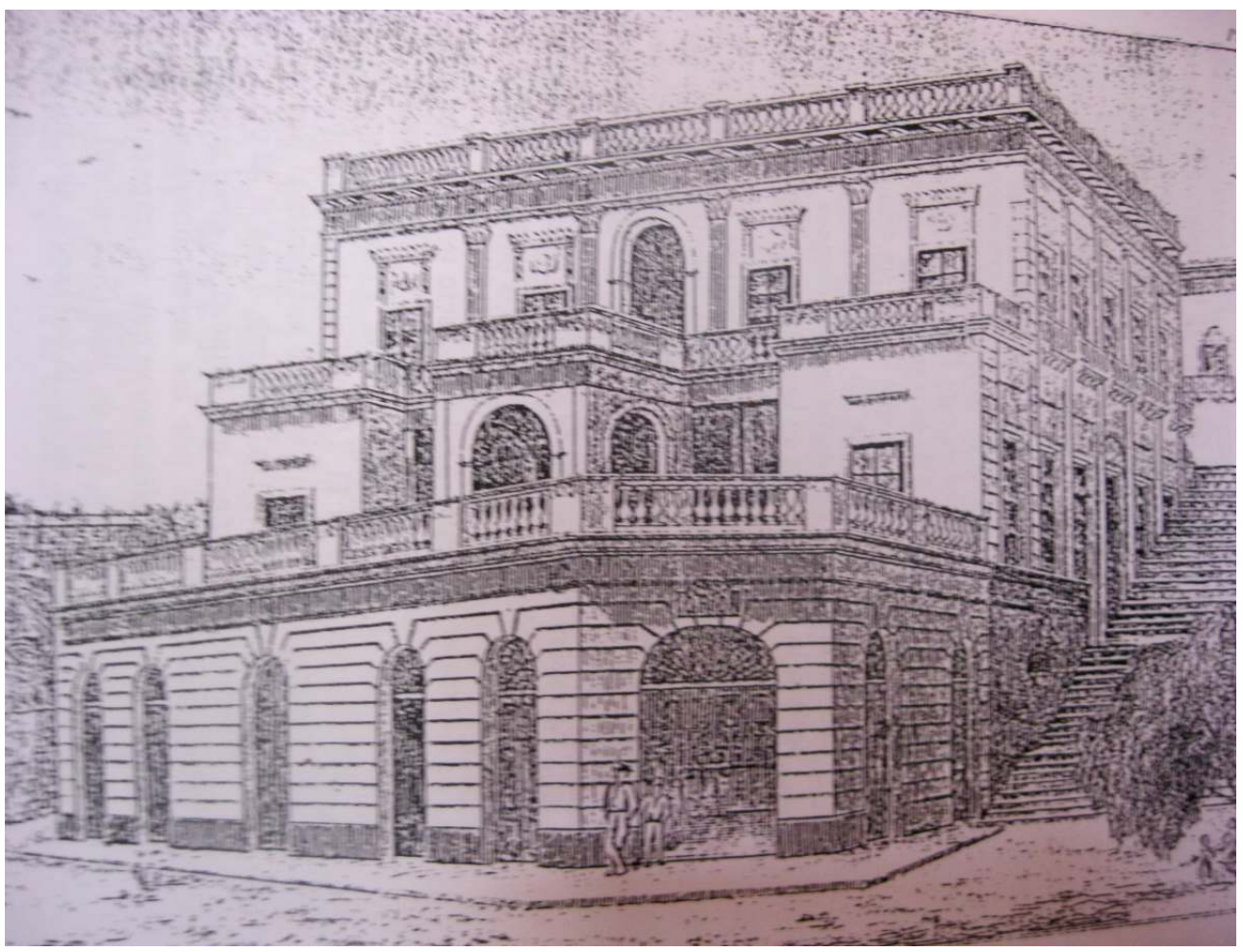

Puerto de Rosario - a. 1900

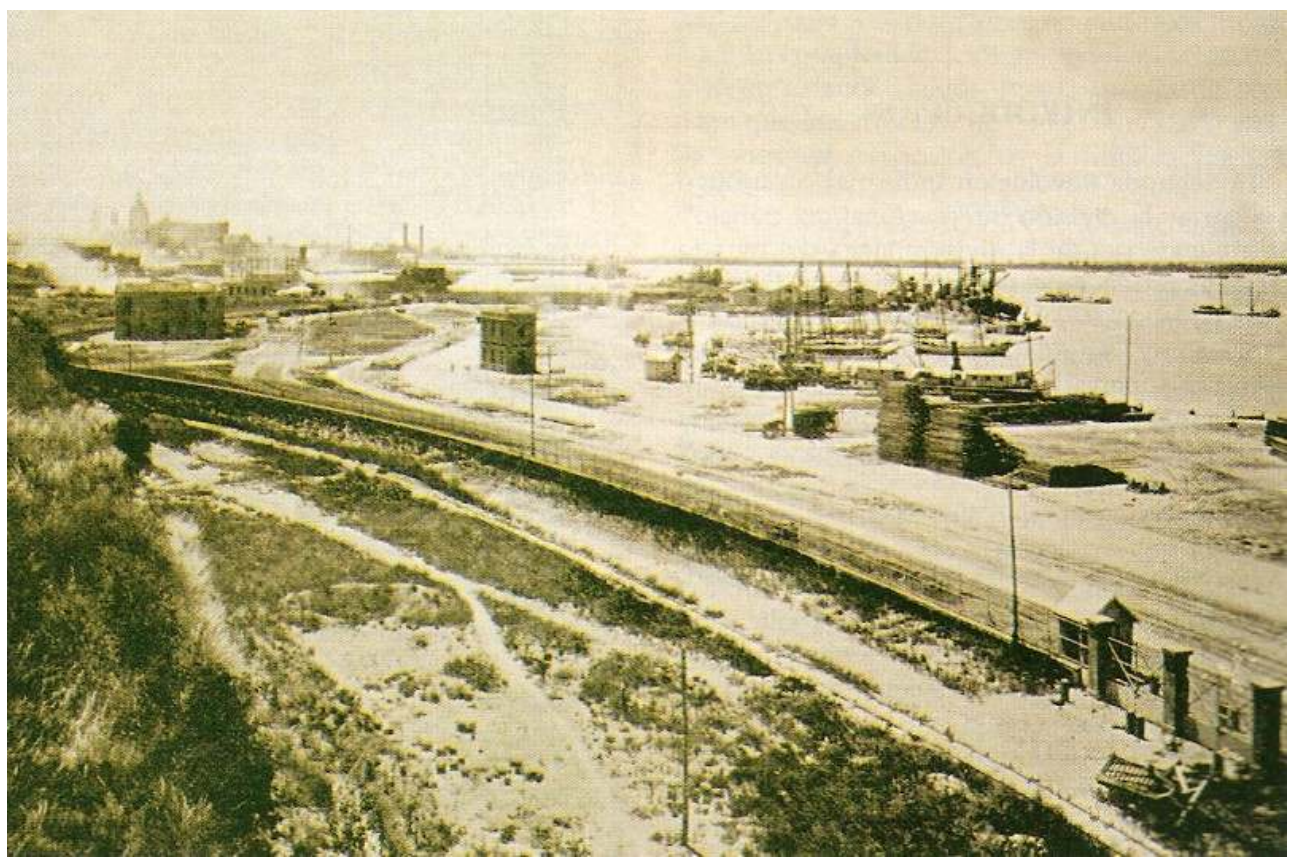


Obras de construcción del puerto moderno de la ciudad - a. 1906

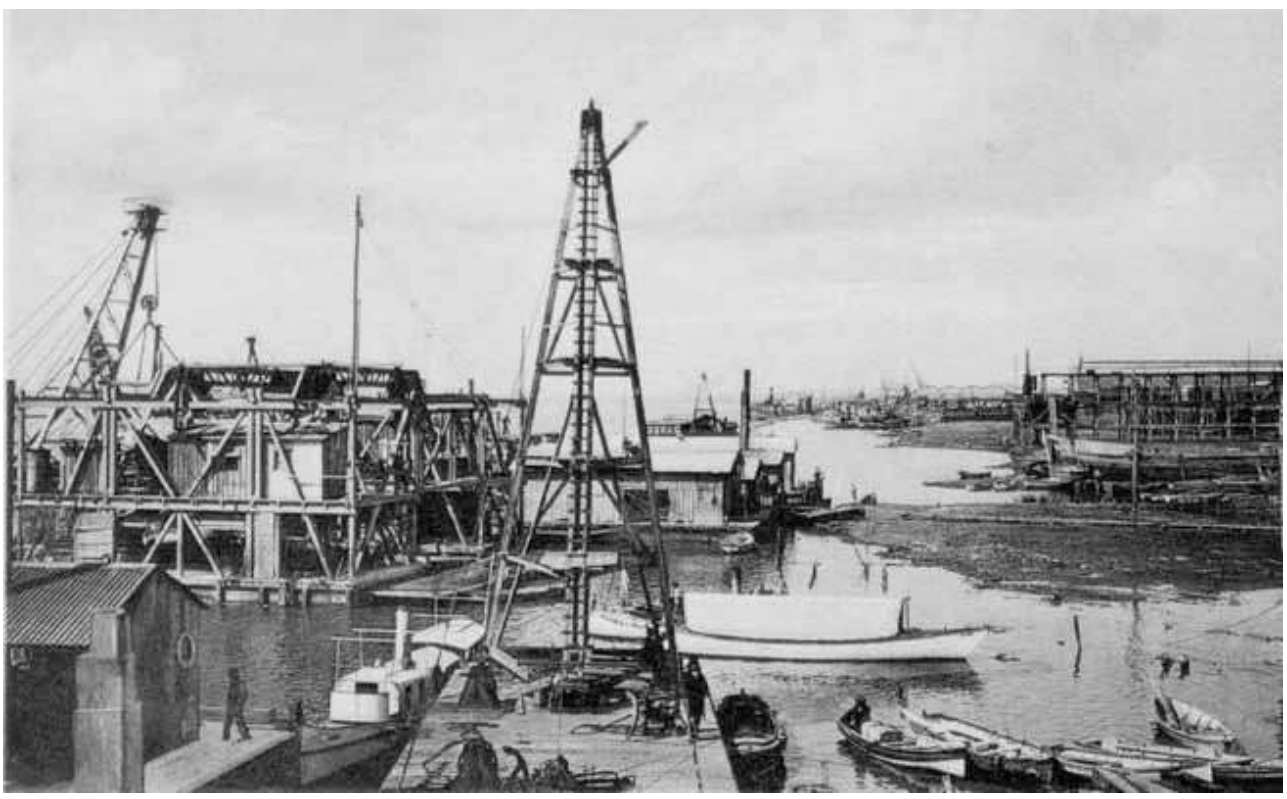

Vista aérea Av. Belgrano y San Juan. Año 1970. Escuela de Museología. El área que se observa, entre la Avenida Belgrano y el Río, se corresponde con el antiguo sector del Bajo.

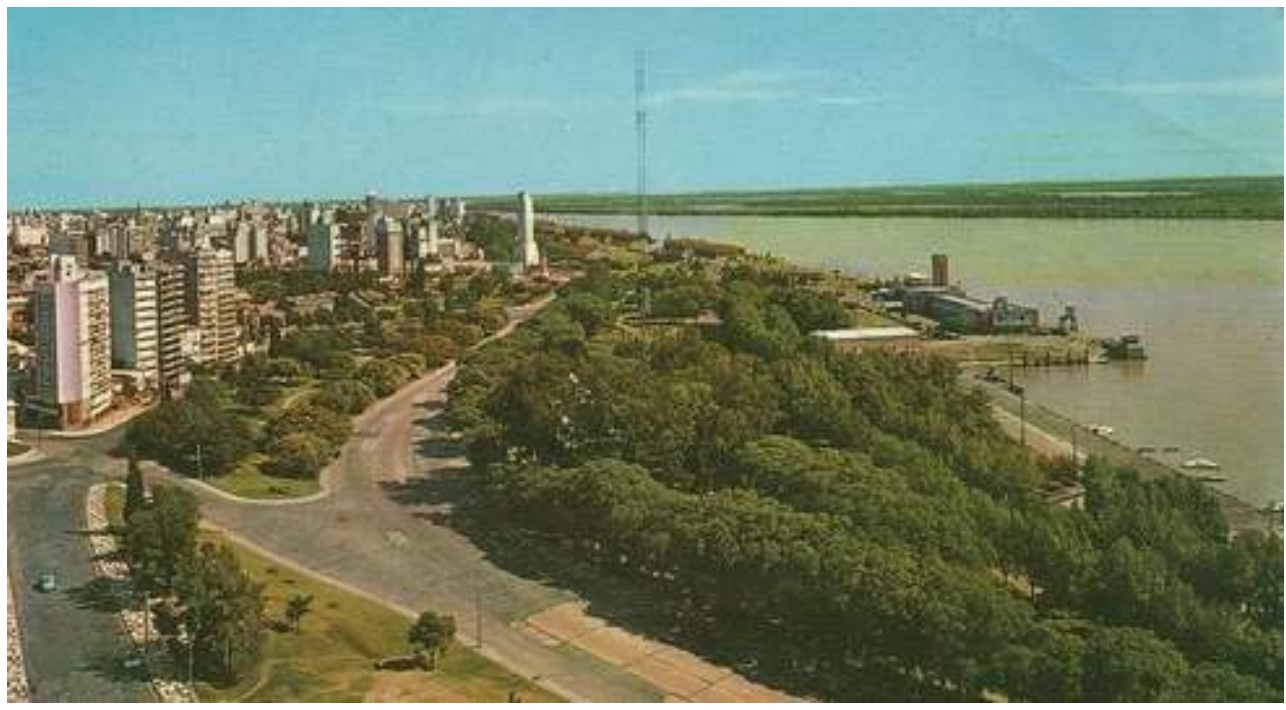

\section{BIBLIOGRAFÍA}

Álvarez, J. (1998). Historia de Rosario (1689-1939). Rosario: UNR. 
Astiz, Ma. E., De Biasi A., Fernández, S. y Silvani, L. (2012). Aporte histórico social de un archivo de agrimensores. El caso del Archivo Torriglia. En II Congreso Nacional de Genealogía del Pago de los Arroyos. Rosario: 18- 20 de octubre.

Avilés, V. D. (1960). Gobernantes de Santa Fe desde 1810 hasta 1960. www.dn11.com.ar /calles/comas\% 20ignacio.htm

Carrasco, G. (1886). Descripción geográfica y estadística de la provincia de Santa Fe. Buenos Aires: Stiller \& Laass.

Dalla Corte, G. (2009). Lealtades firmes. Redes de sociabilidad y empresas: La "Carlos Casado S. A". entre la Argentina y el Chaco paraguayo 1860-1940. Madrid: Consejo Superior de Investigaciones Científicas.

De Marco, M. A. (h.) (1999). La batalla por el puerto de Rosario. Buenos Aires: Ciudad Argentina.

Hourcade, E. (2001). Rosario ciudad-puerto en el siglo XIX, en Falcón, R. y Stanley, M. (directores) La historia de Rosario. Tomo 1: Economía y Sociedad. Rosario: Homo Sapiens. Pp. 273-281.

Lewin, B. (1957) Un documento acerca del comercio intérlope. En El Rosario del siglo XVIII, Anuario del Instituto de Investigaciones Históricas, (№2, pp. 329-369). Rosario: UNL.

Venecia, J. C. (2001). El puerto de Rosario a la vuelta del siglo. En R. Falcón y M. Stanley (Directores), La historia de Rosario. Tomo 1: Economía y Sociedad (pp. 339-345). Rosario: Homo Sapiens.

\section{NOTAS}

1. Centro de Documentación e Información "César Torriglia". Instituto de Investigaciones. Facultad de Humanidades y Artes. Universidad Nacional de Rosario. En la actualidad el equipo académico del Centro de Documentación continúa con la tarea de catalogación de los documentos del corpus en la base de datos computarizada diseñada específicamente para registrar la información contenida en el mismo.

2. Curriculum Vitae, César Torriglia.

3. Carta de cesión en préstamo, marzo de 1966. Procediendo luego a la cesión definitiva del corpus en el año 1973.

4. Jefe Político de la ciudad de Rosario 1893 (Dalla Corte, G., 2009, p. 540)

5. Espacio entre el borde del río que fija las mayores crecientes ordinarias y el límite de las aguas en sus bajantes periódicas. Por ribera externa se entiende aquella parte sobre tierra firme que solo se inunda en crecientes extraordinarias (Documento № 700 "Comas Ignacio. Terreno en Rosario en el bajo a la altura de la calle Rioja".)

6. Es Ernesto Covalier quien luego vende a Manuel Cilvetti.

7. Designado Jefe Político de la ciudad el 5 de febrero de 1859, y presidente del Consejo Ejecutivo Municipal de Rosario en enero de 1874 (Avilés, 1960). 


\section{RESÚMENES}

En consideración a la riqueza de información que atesora el Archivo Cesar Torriglia, nos hemos planteado como objetivo para el presente trabajo ilustrar sobre el valioso aporte del material documental a la historia de las instalaciones portuarias rosarinas procediendo a la selección de informes periciales por juicios de expropiación y reivindicación en terrenos del Bajo de la ciudad, epicentro de la actividad portuaria, sector en donde particulares y la empresa del Ferrocarril Central Argentino reclamaban reconocimiento de sus derechos de posesión a la Sociedad Constructora del Puerto de Rosario con motivo de las obras de construcción del mismo iniciada en 1902.

Considering the richness of information that holds the Cesar Torriglia's Archive this paper intends to show the valuable contribution of its documentary material to the history of Rosario's port facilities, through case selection of expert reports on expropriation trials and claims over the lower part of the city, the center of port activity, where the private sector and the Central Argentine Railway company demanded recognition of their rights of ownership to the Rosario Port Building Society which started its construction in 1902.

\section{ÍNDICE}

Keywords: Archive, Rosario, Port, Economy

Palabras claves: Archivo, Rosario, Puerto, Economía

\section{AUTORES}

\section{RICARDO V. ACURSSO}

CDICT - Instituto de Investigaciones - FHyA. - UNR. Correo electrónico raspissa46@gmail.com

\section{ADRIANA DE BIASI}

CONICET- CDICT Instituto de Investigaciones - FHyA. - UNR. Correo electrónico

adebiasi@arnet.com.ar

\section{SOFÍA FERNÁNDEZ}

CDICT - Instituto de Investigaciones - FHyA - UNR. Correo electrónico soff84@yahoo.com.ar

\section{LUCRECIA SILVANI}

CDICT - Instituto de Investigaciones - FHyA. - UNR. Correo electrónico

lucreciasilvani@hotmail.com 